\title{
VISITAS GUIADAS AO MUSEU NACIONAL: INTERAÇÕES E IMPRESSÕES DE ESTUDANTES DA EDUCAÇÃO BÁSICA
}

\section{Guided visits to National Museum: interactions and impressions of Basic Education students}

\author{
Guilherme Cordeiro da Graça de Oliveira ${ }^{1}$. Cássia Curan Turci ${ }^{2}$ \\ - Brunno Martins Teixeira ${ }^{3}$. Ediléa Mendes de Andrade Silva ${ }^{4}$ \\ - Ivie Soares Garrido ${ }^{5}$. Rafael Silva Moraes ${ }^{6}$
}

Resumo: Este trabalho envolve o planejamento, execução e avaliação de visitas guiadas ao Museu Nacional da Universidade Federal do Rio de Janeiro, por parte de alunos da rede pública do município do Rio de Janeiro. O referencial teórico considera o Modelo de John Falk, com seus aspectos pessoal, físico e sociocultural como facilitadores da aprendizagem em museus. O principal objetivo consistiu em analisar as visitas dos estudantes ao museu quanto à aprendizagem, motivação e ganhos afetivos. Procurou-se, também, estabelecer o Museu Nacional como um espaço para a elaboração de aulas não formais de química. Questionários foram aplicados antes, durante e depois das visitas. Os resultados obtidos permitiram concluir que o procedimento e a dinâmica desenvolvidos proporcionaram ganhos afetivos e cognitivos aos alunos visitantes, e que o contexto físico do Museu Nacional favorece a elaboração de aulas não formais de química, sobretudo para os alunos de nível Médio.

Palavras-chave: Educação em química. Ensino Médio. Espaços não formais. Museu Nacional (RJ).

\begin{abstract}
This work involved the planning, implementation and evaluation of guided visits by public school students from the municipality of Rio de Janeiro to the National Museum of Federal University of Rio de Janeiro (UFRJ). The theoretical background is the Contextual Model of Learning with its personal, physical and sociocultural contexts as facilitators of learning in museums. The main objective was to analyze the visits in relation to learning, motivation and affective gains. It was also aimed to establish the National Museum as a setting for the development of a non-formal school chemistry class. Questionnaires were administered before, during and after visits. The results showed that the procedure and dynamic developed were able to provide cognitive and affective gains for the students. The physical context of the National Museum promotes the development of non-formal classes in Chemistry, especially for high school students.
\end{abstract}

Keywords: Chemistry Education. High school. Non-formal education settings. National Museum (RJ).

\footnotetext{
${ }^{1}$ Universidade Federal do Rio de Janeiro (UFRJ), Instituto de Química, Departamento de Físico-Química, Cidade Universitária, Centro de Tecnologia, bloco A, sala 408, CEP 21949-900, Rio de Janeiro, RJ, Brasil. E-mail: cordeiro@iq.ufrj.br

${ }^{2}$ Universidade Federal do Rio de Janeiro (UFRJ), Instituto de Química, Departamento de Química Inorgânica, Rio de Janeiro, RJ, Brasil.

3,4,5,6 Universidade Federal do Rio de Janeiro (UFRJ), Instituto de Química, Departamento de Físico-Química, Rio de Janeiro, RJ, Brasil.
} 


\section{Introdução}

Os Parâmetros Curriculares Nacionais do Ensino Médio (PCNEM) têm por objetivo central facilitar a organização do trabalho da escola. A ideia é orientar a transformação do Ensino Médio, estabelecendo-o como etapa conclusiva da Educação Básica, e não mais como simplesmente preparatório para o Ensino Superior ou estritamente profissionalizante. Portanto, a programação de aulas curiosas, agradáveis, interessantes, interdisciplinares e contextualizadas não só é lei, como, também, é um direito do aluno. Por sua vez, as Orientações Curriculares para o Ensino Médio recomendam o desenvolvimento de práticas fora do espaço escolar, apontando esse procedimento como atividade motivadora, já que desloca o ambiente de aprendizagem para fora de sala de aula (BRASIL, 2006).

Contudo, a realidade da tradição escolar está muito longe do que seria necessário para que essa nova escola cumpra as orientações dos PCNEM. A realidade nos traz atividades padronizadas sem inserção em contextos reais, colocando os alunos em atitude de passividade frente ao aprendizado. Não são preocupações escolares as perspectivas profissionais, sociais ou pessoais dos alunos, ou os problemas e desafios da comunidade, da cidade, do país ou do mundo. Na escola, de modo geral, o indivíduo interage com um conhecimento essencialmente acadêmico, sobretudo através da transmissão de informações, supondo que o estudante, memorizando-as passivamente, adquira o conhecimento desejado.

Para combinar a visão sistêmica do conhecimento e a formação da cidadania através do ensino de Química, há a necessidade de se reorganizarem os conteúdos químicos atualmente ensinados, bem como a metodologia empregada. É importante apresentar, ao aluno, fatos concretos, observáveis e mensuráveis, uma vez que os conceitos que o aluno traz para a sala de aula advêm, sobretudo, de sua leitura do mundo macroscópico, e como o ensino de química visa, especialmente, contribuir para a formação da cidadania, deve permitir o desenvolvimento de conhecimentos e valores que possam servir de instrumentos mediadores da interação do indivíduo com o mundo. Ou seja, é preciso que se desenvolva uma educação científica crítica e realista para assim contribuir para a superação dos desafios colocados.

Ao abordar um tema que permita a contextualização do conhecimento, mais do que fonte desencadeadora do conhecimento específico é preciso que ele seja visto como instrumento para uma primeira leitura integrada do mundo com as lentes da química. Este parece ser um dos objetivos dos PCNEM.

Diversos pesquisadores afirmam que a educação em ciências, nos dias de hoje, não pode mais se ater ao contexto estritamente escolar. Essa afirmação enfatiza o papel de espaços não formais de educação, tais como: jardins botânicos, parques ecológicos, zoológicos, museus, casas de cultura etc., onde os conteúdos curriculares possam ser trabalhados de forma lúdica e contextualizada e, aos alunos, sejam oferecidas oportunidades de interação com o meio ambiente e a sociedade (JACOBUCCI; JACOBUCCI; MEGID NETO, 2009; MARANDINO, 2009; ROCHA; LEMOS; SCHALL, 2007; VALENTE; CAZELLI; ALVES, 2005).

Além disso, tendo em vista a realidade das escolas públicas do Estado do Rio de Janeiro, os museus oferecem a oportunidade de suprir, ao menos em parte, algumas de suas carências, como a falta de laboratórios, de recursos audiovisuais, entre outros, conhecidos por estimular o aprendizado. Vieira, Bianconi e Dias (2005) realizaram uma avaliação quantitativa do aprendizado de conteúdos de ciências com alunos do segundo segmento do Ensino Fundamental que participaram de aulas não formais realizadas em diferentes espaços, no Rio de 
Janeiro. A avaliação mostrou que as aulas constituíram um aspecto importante no processo de aprendizagem dos conteúdos abordados, além de terem sido reconhecidas como estimulantes pelos alunos. Os resultados sugeriram que, quando bem direcionados, espaços não formais de ensino podem ser bons aliados das aulas formais.

Desta forma, o principal objetivo deste trabalho consiste em analisar as visitas dos estudantes ao museu quanto à aprendizagem, motivação e ganhos afetivos, e identificar possíveis particularidades em função da escolaridade. Procurou-se, também, estabelecer o Museu Nacional como um espaço não formal, potencialmente motivador, para a elaboração de visitas guiadas com objetivos educacionais.

\section{Museus como espaços não formais de educação - aprendizagem em museus}

Embora não haja consenso com relação à definição do que vem a ser um espaço não formal de educação, adota-se aqui a definição segundo a qual tal espaço pode ser qualquer local, diferente do ambiente escolar, institucional ou não, onde se podem exercer atividades educativas. Por outro lado, uma atividade de educação não formal é toda aquela organizada fora do sistema escolar oficial, o qual é obrigatório e regulamentado em níveis. Esta ocorre de maneira voluntária, não sequencial, flexível e guiada por necessidades e motivações intrínsecas do indivíduo (CONSEIL DE L’ÉUROPE, 2007; GOHN, 2006).

Vários autores nacionais e estrangeiros reconhecem um museu de ciências como um dos principais espaços não formais para a produção e o aperfeiçoamento do conhecimento (CARVALHO, 1993; COLOMBO JÚNIOR; AROUCA; SILVA, 2009; GRIFFIN, 2004; KRAPAS; REBELLO, 2001; MARANDINO, 2003, 2009; QUEIRÓZ et al., 2002; TAYLOR, 2008). No entanto, a aprendizagem que neles se desenvolve possui particularidades que a distingue da aprendizagem num ambiente formal (BIZERRA, 2009). No ambiente museal, é comum a ideia de que a aprendizagem relaciona-se a aspectos afetivos, motores, lúdicos e sociais e seja influenciada pela percepção, consciência, emoção e memória do visitante (FALCÃO et al., 2003).

Para que visitas de grupos escolares alcancem as metas educacionais esperadas, diversos programas desenvolveram estratégias que aproximam os objetivos educacionais com relação aos ambientes museal e escolar. Um deles é o School-Museum Integrated Learning Experiences in Science (SMILES) descrito por Griffin (1998). O programa apresenta uma abordagem holística do fenômeno da aprendizagem e descreve a complexidade dos fatores envolvidos como um coletivo indissociável, um processo dinâmico ao longo do tempo. É sugerida uma lista de características que devem apresentar qualquer trabalho que vise bons resultados numa visita guiada: participação dos estudantes na escolha de locais e temas; grupos pequenos com certa autonomia de trabalho; oportunidade para descanso físico e mental durante a visita; escolha de atividades complementares às atividades desenvolvidas no museu; possibilidade de compartilhamento das experiências vivenciadas através da promoção de atividades como seminários, oficinas, workshops etc.

Essas características foram discutidas por Bamberger e Tal (2006) num trabalho onde as diferenças entre o processo de aprendizagem formal numa sala de aula e a aprendizagem que se verifica num ambiente não formal foram investigadas. Os autores classificaram as 
visitas a museus por grupos escolares em três tipos: livre escolha (free choice), escolha limitada (limited choice) e sem escolha (no choice). A visita do tipo livre escolha é aquela na qual os estudantes são livres para escolher qualquer parte da exposição que desejarem e a mediação se resume em responder às questões formuladas. Os autores classificaram as visitas do tipo escolha limitada em dois subtipos, dependentes da programação preestabelecida. Visitas do tipo escolha limitada 1 restringem o roteiro a uma parte específica do museu onde os estudantes devem executar tarefas de acordo com um tema previamente apresentado. Visitas do tipo escolha limitada 2 não restringem o espaço museal, os estudantes escolhem e controlam o roteiro de acordo com uma programação previamente discutida com o professor ou apresentada pelo museu. Seja do tipo 1 ou do tipo 2 de uma visita escolha limitada, a atuação do mediador ou do guia é basicamente no sentido de ajudar na seleção dos objetos ou locais de investigação e estudos por parte dos alunos visitantes. Visitas do tipo sem escolha caracterizam-se pelo caráter expositivo. O roteiro é limitado por um guia e, normalmente, os estudantes são orientados a assistir a exposição do guia, sem qualquer responsabilidade ou controle sobre os assuntos apresentados. Os autores concluíram que o tipo de visita escolha limitada foi o mais educativo e interessante para os alunos. A visita sem escolha foi cansativa e, frequentemente, os alunos se dispersavam durante as apresentações e havia menos formulações de perguntas. A visita livre escolha foi o tipo considerado mais divertido pelos alunos que participaram da pesquisa, porém, os próprios alunos também afirmaram que, do ponto de vista da aprendizagem, sentiram-se um pouco frustrados. Durante as visitas do tipo escolha limitada, os alunos expressaram um grande envolvimento com os assuntos que estavam sendo tratados.

No modelo de aprendizagem contextual (MAC), Falk e Storksdieck (2005) definem aprendizagem como um esforço direcionado e contextualizado que permita construir significados na direção da resolução de problemas, sobrevivência ou prosperidade no mundo; um diálogo entre o indivíduo e o meio através do tempo que relaciona experiências passadas e atuais. O modelo descreve este diálogo direcionado como um processo/produto de interações que ocorrem em diferentes contextos pessoal, sociocultural e físico, cada um agrupando um grande número de fatores facilitadores da aprendizagem. O Quadro 1 descreve os onze principais fatores que facilitam a aprendizagem, distribuídos nos três contextos descritos.

Quadro 1. Fatores que influenciam e definem a aprendizagem num museu.

\begin{tabular}{|l|l|}
\hline Contexto pessoal & $\begin{array}{l}\text { Motivação e expectativas } \\
\text { Experiência e conhecimentos prévios } \\
\text { Interesse e convicções } \\
\text { Escolha e controle }\end{array}$ \\
\hline Contexto sociocultural & $\begin{array}{l}\text { Mediação social no grupo } \\
\text { Mediação facilitada por outros }\end{array}$ \\
\hline Contexto físico & $\begin{array}{l}\text { Organização antecipada } \\
\text { Orientação do espaço físico } \\
\text { Arquitetura e ambiente } \\
\text { Exposições e conteúdos das legendas } \\
\text { Eventos posteriores e experiências fora do museu }\end{array}$ \\
\hline
\end{tabular}

Fonte: Falk e Storksdieck, (2005). 
O contexto pessoal engloba, sobretudo, as motivações, expectativas e possibilidade de escolha e controle. Neste contexto, a aprendizagem é fortemente influenciada pelos interesses, experiências prévias e convicções do indivíduo.

O contexto sociocultural compreende a mediação social no grupo e/ou facilitada por outros. Uma vez que os indivíduos são produtos de relações sociais e culturais, acredita-se que a aprendizagem em museus esteja fortemente influenciada pelas relações socioculturais que se apresentam nesses espaços. Ressaltam-se aqui as diversas possibilidades de interação de um visitante com os demais, bem como a presença de mediadores, guias ou qualquer outra atividade artística e/ou educacional elaborada para fins de que a visita se torne o mais agradável e prazerosa possível.

O contexto físico também deve ser levado em conta. Com relação à aprendizagem em museus, esse contexto diz respeito a uma série de fatores arquitetônicos que incluem: a iluminação, aglomeração de pessoas, qualidade e quantidade de informações apresentadas, ao acesso a um mapa geral do museu etc.

Considerando, ainda, que a aprendizagem não seja um fenômeno instantâneo, mas um processo acumulativo de aquisição e consolidação de significados, as experiências que ocorrem após as visitas são igualmente importantes. Após a experiência museal, acredita-se que o visitante saia com conhecimentos adicionais que possam reforçar sua compreensão dos eventos que ocorrem ou ocorreram na natureza, no mundo ou na sociedade em geral. Desta forma, os eventos que ocorrem após a visita são também facilitadores da aprendizagem, uma vez que reforçam as experiências museais vivenciadas.

Neste trabalho, o planejamento das visitas ao Museu Nacional procurou contemplar, senão a totalidade, a maioria dos fatores descritos no quadro $1 \mathrm{e}$, assim, propiciar visitas lúdicas e descontraídas, desenvolvendo uma inter-relação amigável mediador/visitante, num ambiente agradável, reconhecidamente facilitador da aprendizagem.

\section{Metodologia}

Com o objetivo de realizar uma descrição detalhada do acervo do Museu Nacional, visitas preliminares foram realizadas sem a presença dos alunos. A importância de se conhecer os museus e as histórias das coleções, visando realizar um efetivo trabalho educativo, foi discutida por Marandino (2009). O Quadro 2 descreve temas, assuntos e peças em exposição de algumas salas do museu, evidenciando as relações com a química, bem como os aspectos históricos, artísticos e culturais que foram abordados durante as visitas.

A população em estudo foi formada por alunos do Centro Integrado de Educação Pública (CIEP) 312 Raul Ryff, situado no bairro de Paciência, Rio de Janeiro. O grupo de alunos visitantes foi dividido entre quatro mediadores (dois professores de química da rede pública estadual e dois alunos do curso de Licenciatura em Química do Instituto de Química da UFRJ). Esta distribuição teve por objetivo permitir um número máximo de oito alunos por mediador. Todos os estudantes tomaram ciência da investigação e assinaram um termo de consentimento livre para participar do estudo. Em caso de estudantes menores de 18 anos, este termo foi assinado pelos pais ou responsável. 
Oliveira, G. C. G. et al.

Quadro 2. Descrição parcial do acervo do Museu Nacional.

\begin{tabular}{|c|c|c|c|c|}
\hline Sala & $\begin{array}{c}\text { Assunto tratado } \\
\text { (tema) }\end{array}$ & Peças em exposição & Relação com a Química & $\begin{array}{l}\text { Aspectos hist ricos, } \\
\text { artísticos e culturais }\end{array}$ \\
\hline $\begin{array}{l}\text { Fósseis do } \\
\text { Continente } \\
\text { Gelado }\end{array}$ & Projeto Paleoantar & $\begin{array}{l}\text { Material utilizado e } \\
\text { coletado. Vídeo da } \\
\text { expedição }\end{array}$ & $\begin{array}{l}\text { Estados Físicos, } \\
\text { Evolução Climática, } \\
\text { Fenômenos Químicos e } \\
\text { Meio Ambiente }\end{array}$ & $\begin{array}{l}\text { Atividades dos } \\
\text { Pesquisadores } \\
\text { relatadas em vídeo. }\end{array}$ \\
\hline Meteoritos & $\begin{array}{l}\text { Como reconhecer } \\
\text { um meteorito }\end{array}$ & $\begin{array}{l}\text { Meteoritos, painéis e } \\
\text { textos explicativos }\end{array}$ & $\begin{array}{l}\text { Sistemas homogêneos e } \\
\text { heterogêneos, } \\
\text { composição e elementos } \\
\text { químicos. }\end{array}$ & $\begin{array}{l}\text { Relação entre o } \\
\text { desenvolvimento dos } \\
\text { países e quantidade } \\
\text { de meteoritos } \\
\text { encontrada. }\end{array}$ \\
\hline Egito Antigo & $\begin{array}{l}\text { Cultura Egípcia, } \\
\text { Múmias e } \\
\text { Mumificação }\end{array}$ & $\begin{array}{l}\text { Múmias, túmulos, } \\
\text { esculturas e estelas. }\end{array}$ & $\begin{array}{l}\text { Materiais, substâncias } \\
\text { utilizadas na } \\
\text { mumificação, na } \\
\text { confecção de esculturas } \\
\text { e na conservação atual } \\
\text { das múmias. }\end{array}$ & $\begin{array}{l}\text { Relação entre } \\
\text { mumificação e posição } \\
\text { ocupada na } \\
\text { sociedade. Aspectos } \\
\text { místicos da } \\
\text { mumificação. }\end{array}$ \\
\hline $\begin{array}{l}\text { Arqueologia } \\
\text { pré- } \\
\text { colombiana }\end{array}$ & $\begin{array}{l}\text { Cultura Indígena - } \\
\text { Incas, Maias e } \\
\text { Astecas. }\end{array}$ & $\begin{array}{l}\text { Animais empalhados, } \\
\text { peças do vestuário, } \\
\text { objetos ornamentais } \\
\text { metálicos }\end{array}$ & $\begin{array}{l}\text { Metais, metais nobres } \\
\text { (mineração e obtenção), } \\
\text { metalurgia, ligas } \\
\text { metálicas, soluções } \\
\text { sólidas. }\end{array}$ & $\begin{array}{l}\text { Utilização de metais } \\
\text { na confecção de jóias } \\
\text { e peças utilitárias. }\end{array}$ \\
\hline $\begin{array}{l}\text { Culturas } \\
\text { Mediterrâneas }\end{array}$ & Temas Diversos & $\begin{array}{l}\text { Afrescos, objetos de } \\
\text { vidro, cerâmica, } \\
\text { porcelana e metal. } \\
\text { Textos explicativos. }\end{array}$ & $\begin{array}{l}\text { Materiais, Substâncias } \\
\text { químicas lançadas no } \\
\text { meio ambiente devido a } \\
\text { fenômenos naturais e } \\
\text { antropogênicos. }\end{array}$ & $\begin{array}{l}\text { Diferenças entre os } \\
\text { materiais utilitários e } \\
\text { artísticos na América } \\
\text { pré-colombiana e na } \\
\text { Europa. }\end{array}$ \\
\hline $\begin{array}{l}\text { Indígenas da } \\
\text { Amazônia }\end{array}$ & $\begin{array}{l}\text { Diferentes tribos } \\
\text { indígenas da } \\
\text { Amazônia }\end{array}$ & $\begin{array}{l}\text { Material cerâmico, } \\
\text { ornamentos, } \\
\text { vestuário, armas e } \\
\text { textos explicativos }\end{array}$ & $\begin{array}{l}\text { Matérias, substâncias } \\
\text { venenosas utilizadas } \\
\text { pelos índios. Funções } \\
\text { químicas. }\end{array}$ & $\begin{array}{l}\text { As diferentes tribos } \\
\text { amazônicas. } \\
\text { Diminuição da } \\
\text { população indígena. }\end{array}$ \\
\hline $\begin{array}{l}\text { Paleontologia } \\
\text { e Evolução }\end{array}$ & $\begin{array}{l}\text { Evolução do } \\
\text { Universo e da vida } \\
\text { na Terra. Eras } \\
\text { Geológicas. }\end{array}$ & $\begin{array}{l}\text { Réplicas e Fósseis } \\
\text { Naturais. Dinossauros } \\
\text { (esqueletose } \\
\text { desenhos), painéis, } \\
\text { vídeo e textos } \\
\text { explicativos. }\end{array}$ & $\begin{array}{l}\text { Processos de formação } \\
\text { e preservação de fósseis. } \\
\text { Carbonização, } \\
\text { Incrustação e } \\
\text { fosfatização. }\end{array}$ & $\begin{array}{l}\text { A existência do } \\
\text { universo e a vida na } \\
\text { Terra. Diferentes } \\
\text { formas de vida em } \\
\text { função da idade do } \\
\text { planeta. }\end{array}$ \\
\hline
\end{tabular}

Fonte: elaborado pelos autores.

Neste trabalho, serão apresentados os resultados e conclusões referentes a cinco visitas, com um total de 118 alunos.

A escolaridade dos alunos visitantes encontra-se detalhada no Quadro 3. Conforme descrito nesta Tabela, os alunos do $9^{\circ}$ ano de Ensino Fundamental, $1^{\circ}, 2^{\circ}$ e $3^{\circ}$ anos do Ensino Médio, serão aqui referenciados como grupos A, B, C e D, respectivamente. 
Visitas guiadas ao Museu Nacional: ...

Cada visita foi realizada com somente um grupo de alunos. Procurou-se manter a mesma rotina para as visitas, a qual se encontra detalhada no Quadro 4. Nesta tabela e na sequência do trabalho, os questionários aplicados antes, durante e após as visitas são referenciados como questionários 1,2 e 3 , respectivamente.

Quadro 3. Escolaridade dos alunos visitantes.

\begin{tabular}{|c|l|c|}
\hline Grupo & \multicolumn{1}{|c|}{ Escolaridade } & № de alunos \\
\hline A & 9o ano Fundamental & 27 \\
\hline B & 1ano Médio & 30 \\
\hline C & 2o ano Médio & 37 \\
\hline D & 3o ano Médio & 24 \\
\hline
\end{tabular}

Fonte: elaborado pelos autores.

Quadro 4. A rotina das visitas

\begin{tabular}{|c|l|}
\hline Horário & \multicolumn{1}{c|}{ Atividades } \\
\hline $7 \mathrm{~h} 20$ & Chegada ao colégio - apresentação dos mediadores eaplicação do questionário 1. \\
\hline $8 \mathrm{~h}$ & Saída do colégio \\
\hline $9 \mathrm{~h} 30$ & Chegada ao Museu - "Passeio pelo Jardim \\
\hline $10 \mathrm{~h}$ & Visita - aplicação do questionário 2 \\
\hline $12 \mathrm{~h}$ & Reunião no auditório do museu - aplicação do questionário 3 \\
\hline $12 \mathrm{~h} 30$ & Retorno ao colégio \\
\hline
\end{tabular}

Fonte: elaborado pelos autores.

Inicialmente, os alunos que voluntariamente concordaram em participar da visita e que estavam de posse do termo de consentimento assinado, eram reunidos numa sala de aula e distribuídos entre os quatro mediadores. Neste momento, os mediadores se apresentavam, descreviam qual seria a rotina da visita e aplicavam o questionário 1. Este questionário procurou avaliar o perfil sociocultural, as expectativas com relação à visita e as impressões dos alunos com relação às aulas de química.

$\mathrm{Na}$ chegada ao museu, os alunos eram convidados a um passeio pelos jardins, ocasião na qual se tem a oportunidade de uma visão panorâmica do antig o Palácio Imperial. Durante o passeio, o mediador descreve os principais fatos históricos relacionados ao palácio. Após o passeio, inicia-se a visita propriamente dita, com a distribuição do questionário 2. Este foi elaborado com base no levantamento do acervo do museu, abrangendo aspectos químicos, históricos, artísticos e culturais cujas respostas podiam ser encontradas, pelos alunos, nos textos ou nos vídeos explicativos, durante a visita. Em cada sala visitada, onde haviam questões a serem respondidas, o mediador reunia o grupo e fazia uma breve explanação visando 
facilitar a compreensão e, consequentemente, motivar a busca pelas respostas. Neste momento, os alunos eram estimulados a buscar, por si próprios, as respostas entre os textos explicativos das peças em exposição. Quando em visita a uma sala onde não haviam questões a serem respondidas, o mediador colocava-se à disposição para eventuais dúvidas ou esclarecimentos.

Após a visita, os alunos se reuniam no auditório do museu, onde o terceiro questionário era aplicado. Este questionário avaliou as interações e impressões dos alunos comparadas às expectativas. Parte do questionário 3 foi elaborada na forma de Escala de Likert. A metodologia de avaliação, através da aplicação de questionários aqui proposta, está de acordo com Colombo Júnior; Arouca e Silva (2009) e Rocha; Lemos e Schall (2007).

\section{Resultados e discussão}

\section{Questionário 1}

As tabelas 1 a 5 apresentam os resultados do questionário 1. Na tabela 1, são apresentadas as características quanto à idade, gênero e prática de atividade remunerada dos alunos visitantes.

\begin{tabular}{|c|c|c|c|}
\hline Grupo & $\begin{array}{l}\text { Idade (anos) } \\
\text { № alunos }\end{array}$ & Gênero (Masc.) & Atividade remunerada \\
\hline$A$ & $\begin{array}{c}14-15 \\
23(85,2 \%)\end{array}$ & $11(40,7 \%)$ & $2(7,4 \%)$ \\
\hline B & $\begin{array}{c}15-16 \\
21(70,0 \%)\end{array}$ & $12(40,0 \%)$ & $3(10,0 \%)$ \\
\hline C & $\begin{array}{c}16-17 \\
28(75,7 \%)\end{array}$ & $12(32,4 \%)$ & $5(13,5 \%)$ \\
\hline $\mathrm{D}$ & $\begin{array}{c}17-18 \\
18(75,0 \%)\end{array}$ & $7(29,2 \%)$ & $12(50,0 \%)$ \\
\hline
\end{tabular}

Fonte: elaborado pelos autores.

Pode-se constatar que, para todos os grupos investigados, a maioria dos alunos encontra-se com idade correspondente à escolaridade. Por exemplo, no Grupo A, 23 alunos, o que corresponde a 85,2 \%, têm entre 14 e 15 anos de idade. Quanto ao gênero, é interessante notar que a porcentagem de meninos diminui de forma contínua de 40,7 \% no Grupo A para 29,2 \% no Grupo D. Quando indagados sobre a prática de alguma atividade remunerada, a porcentagem de alunos que responderam afirmativamente aumentou continuamente de 7,4 \% no Grupo A até 50,0\% no Grupo D.

$\mathrm{Na}$ Tabela 2 são descritos os números de alunos e a porcentagem dos que responderam positivamente às seguintes questões: Você frequenta algum curso fora da escola? Qual(is)?; Já visitou algum Museu? Qual(is)?; Pretende fazer algum curso Superior? Qual? 
Visitas guiadas ao Museu Nacional: ...

Verifica-se que cerca de 1/4 dos alunos frequenta algum curso fora da escola. Quando indagados sobre qual a natureza do curso frequentado, a maioria afirma cursar inglês e/ou informática. Cerca de $60 \%$ dos alunos já visitaram algum museu e mais de $80 \%$ dos alunos, exceto o grupo A, pretendem fazer algum curso Superior. Os cursos Superiores mais citados são engenharia e informática (ciências da computação).

Tabela 2. Caracterização dos Grupos de alunos visitantes quanto à frequência de curso(s) fora da escola, visitas a museus e pretensão de fazer curso Superior.

\begin{tabular}{cccc}
\hline Grupo & Frequenta curso(s) fora da escola? & Já visitou algum Museu? & Pretende fazer curso superior? \\
\hline A & $6(22,2 \%)$ & $17(63,0 \%)$ & $19(70,4 \%)$ \\
B & $10(34,5 \%)$ & $14(46,7 \%)$ & $28(93,3 \%)$ \\
C & $10(27,0 \%)$ & $20(54,0 \%)$ & $31(83,7 \%)$ \\
D & $6(25,0 \%)$ & $15(62,5 \%)$ & $21(87,5 \%)$ \\
\hline
\end{tabular}

Fonte: elaborado pelos autores.

A Tabela 3 refere-se à questão: Cite um ou mais aspecto(s) positivo(s) de suas aulas de química. Os aspectos mais citados são: o professor, a afinidade pela matéria e a possibilidade de aquisição de conhecimento.

Tabela 3. Impressões dos alunos quanto aos aspectos positivos das aulas de química.

\begin{tabular}{crrr}
\hline Grupo & Professor & Afinidade & Aquisição de conhecimento \\
\hline A & $13(48,1 \%)$ & $7(25,9 \%)$ & $4(14,8 \%)$ \\
B & $8(26,7 \%)$ & $9(30,0 \%)$ & $3(10,0 \%)$ \\
C & $11(29,7 \%)$ & $2(5,4 \%)$ & $13(35,1 \%)$ \\
D & $9(37,5 \%)$ & $3(12,5 \%)$ & $7(29,2 \%)$ \\
\hline
\end{tabular}

Fonte: elaborado pelos autores.

O professor é o mais citado entre os alunos dos grupos A e D, enquanto os alunos do grupo B citaram, preferencialmente, a afinidade pela disciplina, e os alunos do grupo C citaram a possibilidade de aquisição de conhecimento. Destacam-se, aqui, alguns depoimentos atribuídos aos alunos A1 e A2:

\footnotetext{
A1: “... um aspecto positivo é que o professor ensina muito bem...” A2: “... gosto das aulas, não gosto do comportamento dos alunos na sala”.
}

A Tabela 4 refere-se à questão: Cite um ou mais aspecto(s) negativo(s) de suas aulas de química. $\mathrm{O}$ aspecto negativo mais citado pelos alunos dos grupos $\mathrm{A}, \mathrm{B}$ e $\mathrm{C}$ foi a dificuldade com a matéria. Para os alunos do final do nível Médio (Grupo D), provavelmente por se tratarem de alunos mais velhos e, por conseguinte, mais experientes e conscientes da importância da experimentação para o ensino de química, a falta de laboratório foi considerada 
Oliveira, G. C. G. et al.

como o principal aspecto negativo das aulas de química. Seguem alguns depoimentos dos alunos:

A3: "Eu adoro as aulas de química, o meu professor é super legal. O negativo é que não tem aulas práticas".

A4: "Aprendo muitas coisas interessantes porém não utilizo para nada".

Tabela 4. Impressões dos alunos quanto aos aspectos negativos das aulas de química.

\begin{tabular}{|c|c|c|c|}
\hline Grupo & Falta de laborat rio & Comportamento da turma & Dificuldades \\
\hline A & $3(11,1 \%)$ & $9(33,3 \%)$ & $10(37,0 \%)$ \\
\hline B & $2(6,7 \%)$ & $x x x$ & $12(40,0 \%)$ \\
\hline C & $6(16,2 \%)$ & $1(2,7 \%)$ & $15(40,5 \%)$ \\
\hline $\mathrm{D}$ & $10(41,7 \%)$ & $2(8,3 \%)$ & $X x x$ \\
\hline
\end{tabular}

Fonte: elaborado pelos autores.

É particularmente importante a fala do aluno A4 afirmando que aprende coisas interessantes, porém não as utiliza para nada, o que revela o caráter descontextualizado da aula em relação à realidade do aluno e uma premente necessidade de reformulação de conteúdos e metodologia.

A Tabela 5 descreve as principais expectativas dos alunos com relação à visita.

Tabela 5. Expectativas dos alunos com relação à visita.

\begin{tabular}{ccrc}
\hline Grupo & Aquisição de conhecimento & Diversão & Interessante \\
\hline A & $16(55,2 \%)$ & $4(13,8 \%)$ & $8(27,6 \%)$ \\
B & $16(51,6 \%)$ & $4(12,9 \%)$ & $6(19,4 \%)$ \\
C & $28(75,7 \%)$ & $4(10,8 \%)$ & $5(13,5 \%)$ \\
D & $18(78,3 \%)$ & $1(4,3 \%)$ & $3(13,0 \%)$ \\
\hline
\end{tabular}

Fonte: elaborado pelos autores.

A expectativa de que a visita possibilite a aquisição de novos conhecimentos foi a mais citada entre os quatro grupos investigados, porém, proporcionalmente, os alunos do Grupo D foram os que mais citaram essa expectativa (78,3\%). Para os alunos mais novos (Grupo A), expectativas de que a visita fosse interessante e/ou divertida foram, proporcionalmente, mais citadas quando comparadas aos outros grupos. É importante salientar que nenhuma resposta apontou para uma expectativa negativa com relação à visita. Nas palavras dos próprios alunos:

A5: "Creio que irei conhecer coisas novas".

A6: "Quero muito ir, estou ansiosa e nervosa, sempre quis ir a um museu". 
Visitas guiadas ao Museu Nacional: ...

\section{Questionário 2}

Para fins desse estudo, foram selecionadas cinco questões que faziam parte do questionário 2. São elas: 1) Qual a temperatura média na Antártica? 2) Qual a composição química do meteorito Pará de Minas? 3) Qual o perigo de se utilizar o bronze como utensílio para cozinhar alimentos? 4) O que é o natrão? 5) Qual a função do natrão na mumificação? A questão 1 é respondida na sala "Fósseis do Continente Gelado", onde contextualizam-se as drásticas mudanças climáticas ocorridas na Antártica devido a causas naturais, com possíveis

alterações climáticas que poderão ocorrer pela ação humana. Na sala "Meteoritos", os alunos recebem informações sobre como diferenciar um meteorito de uma rocha proveniente da crosta terrestre, e encontram a resposta da questão 2. A Questão 3 é respondida ao se visitar a sala "Cultura Mediterrânea", onde diversas peças de bronze estão em exposição. A possibilidade de contextualização aparece aqui ao se abordar o perigo da utilização de panelas com revestimentos antiaderentes de politetrafluoretileno (tefal) desgastados ou danificados. As questões 4 e 5 são tratadas na sala "Cultura Egípcia". Num texto explicativo sobre o processo de mumificação, os alunos encontram a descrição do natrão (nome vulgar do carbonato de sódio hidratado) e sua função como desidratante e desinfetante no processo.

A Tabela 6 apresenta o número e a porcentagem de respostas corretas para cada grupo de alunos. Diferenças importantes apareceram com relação ao nível de acertos das questões 4 e 5 para o Grupo A em comparação aos demais grupos. Aqui o nível de acertos desse grupo de alunos, em torno de $25 \%$, é significativamente menor quando comparado aos níveis obtidos com os demais grupos, entre 70 e $95 \%$. Ao final da descrição dos resultados obtidos, algumas hipóteses serão propostas para justificar esse resultado.

Tabela 6. Número e porcentagem de respostas corretas do questionário 2.

\begin{tabular}{cccccc}
\hline \multicolumn{5}{c}{ Questão/Respostas corretas } \\
\cline { 2 - 6 } Grupo & $\mathbf{1}$ & $\mathbf{2}$ & $\mathbf{3}$ & $\mathbf{4}$ & $\mathbf{5}$ \\
\hline A & $20(74,1 \%)$ & $25(92,6 \%)$ & $16(59,3 \%)$ & $7(25,9 \%)$ & $6(22,2 \%)$ \\
B & $29(96,7 \%)$ & $29(96,7 \%)$ & $23(76,7 \%)$ & $21(70,0 \%)$ & $21(70,0 \%)$ \\
C & $33(89,2 \%)$ & $32(86,5 \%)$ & $29(78,4 \%)$ & $35(94,6 \%)$ & $33(89,2 \%)$ \\
D & $22(91,7 \%)$ & $23(95,8 \%)$ & $19(79,2 \%)$ & $22(91,7 \%)$ & $20(83,3 \%)$ \\
\hline
\end{tabular}

*As questões 1 - 5 estão descritas no texto.

Fonte: elaborado pelos autores.

\section{Questionário 3}

O questionário 3 foi aplicado após a visita e procurou avaliar os ganhos afetivos e cognitivos obtidos. Parte desse questionário foi elaborada em escala de Likert, onde os alunos deveriam atribuir valores de um a cinco numa escala que vai de "discordo totalmente" até "concordo totalmente". As sentenças analisadas, relativas à visita, foram as seguintes: I) Despertou minha curiosidade por algum aspecto da química ou da ciência em geral; II) Não 
trouxe novidade; III) Superou minhas expectativas; IV) Durante a visita, foi difícil encontrar as respostas do questionário, e V) A exposição do mediador foi clara e me facilitou encontrar as respostas. A Tabela 7 apresenta o número e as porcentagens de concordância com relação às sentenças I - V. Para as sentenças I e III, os níveis de concordância foram elevados para todos os grupos investigados, revelando que os alunos obtiveram ganhos afetivos e cognitivos no que se refere à estimulação da curiosidade com relação aos aspectos científicos. A sentença III revela que as expectativas iniciais foram superadas para todos os grupos de alunos. Da mesma forma, o elevado nível de concordância na sentença $V$ revela que o procedimento de mediação adotado foi motivador e facilitador na procura pelas respostas. Os baixos níveis de concordância na sentença II apontam na direção de que a visita foi capaz de aportar novas percepções aos alunos. Com relação à sentença IV, verifica-se que, para os alunos do Grupo A (mais novos), foi mais difícil encontrar as respostas do questionário 2. Nas palavras dos alunos:

A7: "O que eu mais gostei foi a história sobre a Antártica, achei muito interessante pois nunca imaginaria que uma floresta poderia ficar toda congelada e acabar sem vegetação (acabar não sendo mais uma floresta)".

A8: "O que mais despertou minha atenção foi a possibilidade de ver bem de perto o que costumo ter acesso a penas por meio de livros..."

Tabela 7. Níveis de concordância no questionário 3 (escala de Likert).

\begin{tabular}{cccccc}
\hline & \multicolumn{5}{c}{ Sentença/Nível de concordância* } \\
\cline { 2 - 6 } Grupo & I & II & III & IV & V \\
\hline A & $18(66,7 \%)$ & $3(11,1 \%)$ & $22(81,4 \%)$ & $9(33,3 \%)$ & $23(85,2 \%)$ \\
B & $27(90,0 \%)$ & $x x x$ & $25(83,3 \%)$ & $5(16,7 \%)$ & $29(96,7 \%)$ \\
C & $28(75,7 \%)$ & $4(10,8 \%)$ & $33(89,2 \%)$ & $9(24,3 \%)$ & $34(91,9 \%)$ \\
D & $23(95,8 \%)$ & $2(8,3 \%)$ & $20(83,3 \%)$ & $6(25,0 \%)$ & $23(95,8 \%)$ \\
\hline
\end{tabular}

*Respostas 4 e 5 numa escala de 1 para "Discordo Totalmente ; 2 para "Discordo em arte ; 3 para "Não tenho opinião ; 4 para "Concordo em Parte e 5 para "Concordo Totalmente .

Fonte: elaborado pelos autores.

De maneira geral, os resultados obtidos dos questionários 1, 2 e 3 apontam na direção de que todos os grupos de alunos investigados obtiveram ganhos afetivos e cognitivos com a visita. Os fatores previstos no MAC e considerados na elaboração da mediação das visitas favoreceram as especificidades da aprendizagem no ambiente museal. O contexto pessoal foi contemplado ao se procurar contextualizar o discurso do mediador relacionando conteúdos químicos com o cotidiano dos alunos. O contexto sociocultural foi contemplado ao se promoverem interações, entre os estudantes e esses com o mediador, que geraram visitas lúdicas e descontraídas, desenvolvendo um ambiente agradável, reconhecidamente facilitador da aprendizagem. O contexto físico do museu foi mais adequado à aprendizagem dos alunos de nível Médio. De fato, em média, as porcentagens de acertos dos grupos B, C e D, no questionário 2, 
foram, respectivamente, $82,0,87,6$ e $88,3 \%$; enquanto os alunos do grupo A obtiveram somente $54,8 \%$ de respostas corretas (Tabela 6 ).

Uma vez que os resultados obtidos no questionário 3 mostraram que todos os grupos de alunos investigados se manifestaram de forma positiva com relação às impressões relativas ao procedimento e à dinâmica desenvolvidos na mediação (Tabela 7), a hipótese de que o grupo A de alunos estava desestimulado a responder às questões pode ser desconsiderada. Algumas possíveis justificativas para essa diferença no nível de acertos dos alunos do Grupo A podem ser sugeridas. A primeira delas diz respeito ao fato de os alunos desse grupo $\left(9^{\circ}\right.$ ano de nível Fundamental) ainda não estarem familiarizados com os conceitos químicos abordados, tais como sal inorgânico, nomes vulgares das substâncias químicas e função desidratante. Outra possível justificativa aparece ao se analisarem os textos explicativos onde as respostas são encontradas. A Figura 1 apresenta os textos em exposição onde são encontradas as respostas das questões 3,4 e 5 do questionário 2 .

Figura 1. Textos explicativos onde se encontravam as respostas das questões 3 (Figura 1A) e questões 4 e 5 (Figura 1B).

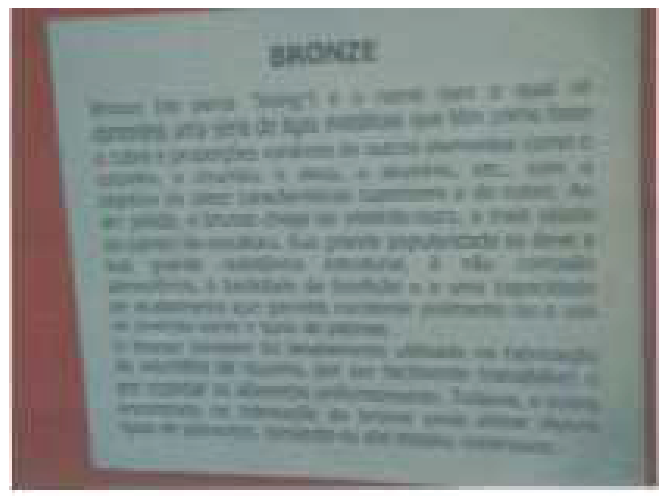

(A)

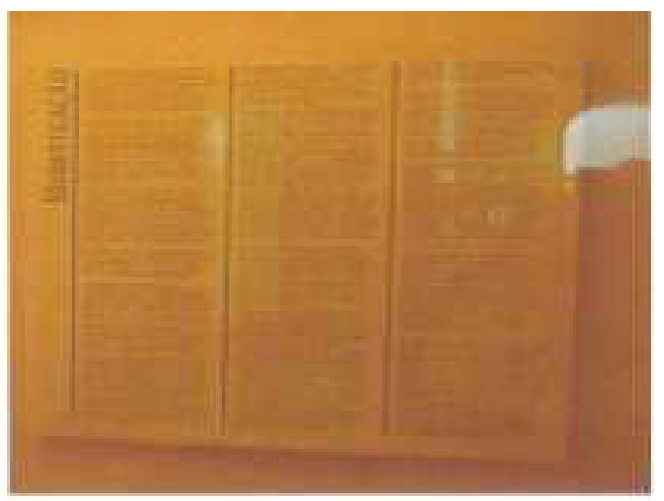

(B)

Dimensões aproximadas: Figura 1A: 40 x 50 cm; Figura 1B: 150 x $100 \mathrm{~cm}$.

Fonte: acervo do Museu Nacional (RJ).

Como pode ser observado, o texto onde se encontram as respostas das questões 4 e 5 (Figura 1B) é consideravelmente maior que o texto onde se encontra a resposta da questão 3 (Figura 1A). Tendo em vista as sérias deficiências com relação à leitura e interpretação de texto apresentadas pelos alunos do final do nível Fundamental, essa discrepância no nível de acertos do questionário 2 poderia ser atribuída à dificuldade de leitura apresentada por esses estudantes. Embora esse tema não tenha sido investigado no presente trabalho, resultados obtidos na literatura reforçam a hipótese sugerida (GIAMBIAGI, REIS; URANI, 2004; TEIXEIRA, 2009). 


\section{Conclusões}

Tendo em vista os resultados apresentados nesse trabalho, chega-se às seguintes conclusões:

(i) O procedimento e a dinâmica desenvolvidos durante as visitas foram capazes de proporcionar ganhos afetivos e cognitivos aos alunos visitantes.

(ii) $\mathrm{O}$ menor índice de acertos entre os alunos de $9^{\circ}$ ano de Ensino Fundamental pode estar relacionado ao fato de esses alunos ainda não estarem familiarizados com conceitos químicos abordados e, também, às dificuldades em leitura e interpretação dos textos explicativos reveladas durante a visita.

(iii) O Museu Nacional como um espaço não formal para ensino de química revela-se uma opção promissora capaz de atenuar, ao menos em parte, as deficiências estruturais apresentadas na rede pública de ensino.

(iv) O contexto físico do Museu Nacional favorece a elaboração de aulas não formais de química, sobretudo, para os alunos de nível Médio.

\section{Agradecimentos}

Os autores agradecem à Fundação de Amparo à Pesquisa do Estado do Rio de Janeiro (FAPERJ); ao Programa Institucional de Bolsas de Extensão (PIBEX), PR5 - UFRJ e ao Centro Integrado de Educação Pública (CIEP) 312 Raul Ryff.

\section{Referências}

BAMBERGER, Y.; TAL, T. Learning in a personal context: levels of choice in a free choice learning environment in science and natural history museum. Science Education, Hoboken, v. 91, n. 1, p. 75-95, 2006.

BIZERRA, A. Atividade de aprendizagem em museus de ciência. 2009. 274 f. Tese (Doutorado em Educação) - Faculdade de Educação, Universidade de São Paulo, São Paulo, 2009.

BRASIL. Ministério da Educação. Secretaria da Educação Média e Tecnológica.

Parâmetros curriculares nacionais: ensino médio. Brasília, 1999.

Ministério da Educação. Secretaria da Educação Média e Tecnológica.

Orientações curriculares para o ensino médio: ciências da natureza, matemática e suas tecnologias. Brasília, 2006.

CARVAlHO, A. G. Os museus e o ensino de ciências. Revista de Educação, Lisboa, v. 3, n. 1, p. 61-66, 1993.

COLOMBO JÚNIOR, P.; AROCA, S.; SILVA, C. Educação em centros de ciências: visitas escolares ao observatório astronômico do CDCC/US. Investigações em Ensino de Ciências, Porto Alegre, v. 14, n. 24, p. 25-36, 2009. 
Visitas guiadas ao Museu Nacional: ...

CONSEIL DE L’EUROPE. Direction de la Jeunesse et du Sport. Mini-compendium de 1'éducation non-formelle. Strasbourg, 2007.Disponível em: <http://www.coe.int/t/dg4/ youth/Source/Resources/Portfolio/Compendium_NFE_fr.pdf> Acesso em: 12 jan. 2010.

FALCÃO, D. et al. Museus de ciências, aprendizagem e modelos mentais: identificando relações. In: GOUVÊA, G.; MARANDINO, M.; LEAL, M. (Org.). Educação e museus: a construção social do caráter educativo dos museus de ciências. Rio de Janeiro: FAPERJ, 2003. p.185-206.

FALK, J.; STORKSDIECK, M. Learning science from museums. História, Ciência e Saúde, Rio de Janeiro, v. 12, p. 117-198, 2005. (Suplemento).

GIAMBIAGI, F.; REIS, J.; URANI, A. (Org.). Reformas no Brasil: balanço e agenda. Rio de Janeiro: Nova Fronteira, 2004.

GOHN, M. Educação não formal, participação da sociedade civil e estruturas colegiadas nas escolas. Ensaio: avaliação e políticas públicas em educação, Rio de Janeiro, v. 14, n. 50, p. 27-38. 2006. Disponível em: <http://www.scielo.br/ scielo.php?script=sci_arttext\&pid=S0104-40362006000100003 >. Acesso em: 02 jun. 2010.

GRIFFIN, J. M. School-museum integrated learning experiences in science. 1998. 376 f. Thesis (Doctor of Philosophy) - University of Technology, Sidney, 1998. Disponível em: <http://epress.lib.uts.edu.au/research/handle/10453/20150>. Acesso em: 04 fev. 2014.

. Research on students and museums: looking more closely at the students in school groups. Science Education, Honoken, v. 88, n. S1, p. S59-S70, 2004.

JACOBUCCI, D. F. C.; JACOBUCCI, G. B.; MEGID NETO, J. Experiências de formação de professores em centros e museus de ciências no Brasil. Revista Electrónica de Enseñanza de las Ciencias, Vigo, v. 8, n.1, p. 118-136, 2009. Disponível em: <http:// reec.uvigo.es/volumenes/volumen8/ART7_Vol8_N1.pdf>. Acesso em: 03 fev. 2014.

KRAPAS, S.; REBELLO, L. O perfil dos museus de ciências da cidade do Rio de Janeiro: a perspectiva dos profissionais. Revista Brasileira de Pesquisa em Educação em Ciências, Belo Horizonte, v. 1, n. 1, p. 68-87, 2001.

MARANDINO, M. Enfoques de educação e comunicação nas bioexposições de museus de ciências. Revista Brasileira de Pesquisa em Educação em Ciências, Belo Horizonte, v. 3, n.1, p. 103-120, 2003.

- Museus de ciências, coleções e educação: relações necessárias. Museologia e Patrimônio, Rio de Janeiro, v. 2, p. 1-12, 2009.

QUEIRÓZ, G. et al. Construindo saberes da mediação na educação em museus de ciências: o caso dos mediadores do museu de astronomia e ciências afins. Revista Brasileira de Pesquisa em Educação em Ciências, Belo Horizonte, v. 2, p.77-88, 2002. 
Oliveira, G. C. G. et al.

ROCHA, V.; LEMOS, E.; SCHALL, V. A contribuição do Museu da Vida para a educação não formal em saúde e ambiente: uma proposta de produção de indicadores para elaboração de novas atividades educativas. In: REUNIÓN DE LA RED DE POPULARIZACIÓN DE LA CIENCIA Y LA TECNOLOGÍA EN AMÉRICA LATINA Y EL CARIBE, 10., 2007, San Jose, Costa Rica. Disponível em: <http:// www.cientec.or.cr/pop/2007/BR-VaniaRocha.pdf>. Acesso em: 04 fev. 2014.

TAYLOR, E.; NEILL, A. Museum education: a nonformal perspective. Journal of Museum Education, Chicago, v. 33, n. 1, p. 23-32, 2008.

TEIXEIRA, R. Espaços, recursos escolares e habilidades de leitura de estudantes da rede pública municipal do Rio de Janeiro. Revista Brasileira de Educação, Rio de Janeiro, v. 14, n.41, p. 232-245, 2009.

VALENTE, M.; CAZELLI, S. ALVES, F. Museus, ciência e educação: novos desafios. História, Ciência e Saúde, Rio de Janeiro, v. 12, p. 183-203, 2005. (Suplemento).

VIEIRA,V.; BIANCONI, L.; DIAS, M. Espaços não-formais de ensino e o currículo de ciências. Ciência e Cultura, São Paulo, v. 57, n. 4, p. 21-23. out/dez, 2005. Disponível em: $<$ Disponível em: < http://cienciaecultura.bvs.br/pdf/cic/v57n4/a14v57n4.pdf > Acesso em: 04 fev. 2014.

Artigo recebido em 03/04/13. Aceito em 04/09/13. 